\title{
Comparison of ARCHER MPERC to NHC Analysis
}

\author{
Lorenzo Pulmano ${ }^{1}$ and Leya Joykutty"\# \\ ${ }^{1}$ American Heritage School, Plantation, FL, USA \\ \#Advisor
}

\section{ABSTRACT}

Eyewall replacement cycles (ERCs) are events that occur in intense tropical cyclones (TCs) and are difficult to predict. An ERC event involves a secondary outer eyewall that surrounds the inner eyewall. The outer eyewall slowly moves towards the eye and weakens the inner eyewall, eventually replacing the inner eyewall. During this process, wind speeds lower and the structure of a TC becomes disorganized, further weakening the storm. TCs often restrengthen after an ERC. Little is known about the process and as such, poses an obstacle to forecasters. The Automated Rotational Center Hurricane Eye Retrieval (ARCHER) Microwave-based Probability of Eyewall Replacement Cycle (MPERC) is an algorithm that uses $89-95 \mathrm{GHz}$ passive microwave imagery and intensity estimates from the National Hurricane Center (NHC), Central Pacific Hurricane Center (CPHC), or the Joint Typhoon Warning Center (JTWC) to predict the possibility of an ERC. The effectiveness and ability of ARCHER MPERC was analyzed and compared to the NHC's official reports on all Atlantic Basin tropical cyclones from 2017 to 2019.

MPERC ultimately predicted seventeen ERCs in nine tropical cyclones. Of those, seven were valid ERCs. The algorithm works well, predicting approximately $41 \%$ of the total number of predictions correctly. However, MPERC did not predict five ERCs that were cited by the NHC. It was further found that it was true that MPERC produces incorrect results in sheared and dry environments.

\section{Introduction}

The purpose of this paper is to evaluate and compare the predictions of eyewall replacement cycle (ERC) events derived from the Automated Rotational Center Hurricane Eye Retrieval (ARCHER) Microwave-based Probability of Eyewall Replacement Cycle (MPERC) to official NHC reports on all North Atlantic Basin tropical cyclones (TCs) from 2017 to 2019.

An eyewall replacement cycle occurs when a secondary eyewall forms and eventually replaces the inner eyewall. It is a common occurrence in intense TCs. The outer eyewall forms from outer rainbands and gradually moves inward and weakens the inner eyewall. Because of this, storms often weaken with a drop in wind speed and structure change; however, they may re-intensify after it is complete and reorganizes. ERCs are difficult to predict in intensity forecasting because little is known about the genesis and process (Zhou \& Wang, 2011).

ERCs can be observed from satellite imagery. The convection of the concentric eyewalls can be visible. During an event, the convection of the inner eyewall wanes while the convection of the secondary eyewall grows stronger. Associated changes in the wind maximum and vorticity also occur (Molinari et al., 2019). However, the wind field often expands, thereby exposing more water to wind and causing more destructive storm surge (Sitkowski et al., 2011). The effects can be felt around a basin. For example, Hurricane Lorenzo from 2019 generated large swells and rip currents, causing 8 deaths along the east coast of the US, despite its location in the far east of the Atlantic (Zelinsky, 2019b).

The re-intensification phase after an ERC can sometimes erupt as rapid intensification (RI). Referring to Sitkowski et al. (2011): 
[T]he contraction of an outer eyewall near the end of an ERC can sometimes lead to rapid intensification resulting in a more intense hurricane than when the ERC began. This was the case for Hurricane Andrew (1992), which intensified to a category 5 hurricane as it approached the southeast coast of Florida during the end of an ERC.

\section{Automated Rotational Center Hurricane Eye Retrieval (ARCHER)}

ARCHER is an algorithm that finds the center of rotation of a TC using temperature gradients in TC banding patterns in addition to gradients bordering an eye. $85-92 \mathrm{GHz}$ passive microwave imagery is used to calibrate and validate ARCHER (Wimmers \& Velden, 2010). According to "Highlights" (n.d.), ARCHER is designed to:

aid tropical cyclone forecasters in sifting through the increasing wealth of relevant satellite data to quickly and objectively arrive at key TC characteristics... to increase efficient use of analysis time.

A component of ARCHER is the spiral score. It is a measure of how gradients in an image align with a spiral vector field. The center location of a spiral vector field that aligns best with the image gradients is where the spiral score reaches a maximum. The algorithm uses the cross product of the amount of alignment between image gradients and the spiral vector field ("How ARCHER works," n.d.).

Ring Score measures "the best fit of the gradients of an inner eyewall (if it exists) to a circular shape" ("How ARCHER works," n.d.). The maximum score is located at the center of the best-fit circle. It computes the mean dot product of image gradient and normalized radius vector of points on the best-fit circle. It is noted that there is added weight on larger radii eyewalls "to compensate for the effects of their higher eyewall irregularity" ("How ARCHER works," n.d.). In a grid, it would be shown in three dimensions in latitude, longitude, and the radius. The maximum value of radius is depicted on a $2 \mathrm{D}$ plot.

Distance penalty is a component that "spiral score fields into 'guided' spiral scores" (Wimmers \& Velden, 2010). It is a check to correct any results from images.

The combined score grid is "a weighted sum of the spiral score grid, ring score grid, and distance penalty grid" ("How ARCHER works," n.d.).

\section{Microwave-based Probability of Eyewall Replacement Cycle (MPERC)}

MPERC utilizes the ARCHER Ring Score, Probability of ERC onset, and Operation Vmax. The Probability of ERC onset is the "model-estimated chance that the intensity forecast will be affected by an ERC" ("M-PERC introduction, " n.d.). Operational Vmax is the latest estimate of the intensity from the National Hurricane Center (NHC), Central Pacific Hurricane Center (CPHC), or Joint Typhoon Warning Center (JTWC) for the appropriate basins. MPERC Full Model is a logistical regression model that uses the most recent 24 hours of Ring Score and the Operational Vmax as predictors. It was calibrated using only North Atlantic Basin storms from 1999-2011; however, it appears to be useful in basins where TC size is similar to North Atlantic TCs and is less effective when used on smaller storms or large monsoon genesis events ("M-PERC introduction, " n.d.).

It is best to assign ERC onset when the probability crosses $50 \%$ (Figure 1). Changes accompanied with ERC events should be expected within the next 20-50 hours, with the average start of weakening at 9 hours since onset and the average start of re-intensification at 20 hours since onset ("M-PERC introduction," n.d.). 


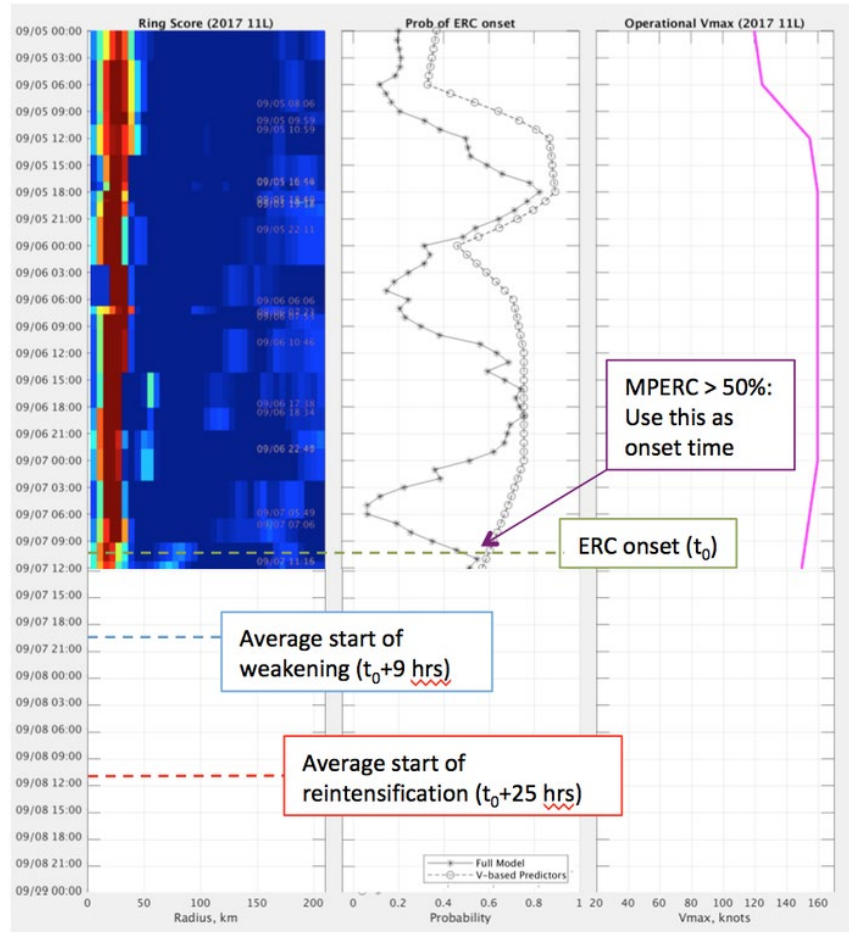

Figure 1. Analyzing a hovmuller ("M-PERC introduction," n.d.)

Currently, MPERC has two known weaknesses: it underestimates the probability of ERC onset for TCs with eyewalls greater than $60 \mathrm{~km}$ in diameter, and it can generate false positives of high-ERC probability in heavily sheared environments. The former stems from the fact that the model used training data with a large sample of smaller primary eyewalls. The latter is "because of the noisier gradients in convection-free regions" ("M-PERC introduction," n.d.).

Determining the effectiveness of ARCHER MPERC and, in general, the ability in predicting ERCs is crucial for forecasting.

\section{The Evolution of ARCHER MPERC}

Starting in July 2015, ARCHER MPERC was sponsored by the Joint Hurricane Testbed (JHT). The purpose of the JHT is:

to transfer more rapidly and smoothly new technology, research results, and observational advances of the United States Weather Research Program (USWRP), its sponsoring agencies, the academic community and other groups into improved tropical cyclone analysis and prediction at operational centers. ("JHT

Overview," n.d.)

The principal investigators were Anthony "Tony" Wimmers and Derrick Herndon from the Cooperative Institute for Meteorological Satellite Studies (CIMSS) at the University of Wisconsin - Madison, and Jim Kossin from National Oceanic and Atmospheric Administration (NOAA) National Centers for Environmental Information (NCEI) Center for Weather and Climate, Asheville, North Carolina.

Under 2016 Mid-year reports, Wimmers submitted a report (Wimmers, 2016a) for reporting period $1 \mathrm{Au}-$ gust 2015 to 28 February 2016. In summary, progress was made in creating a "double eyewall module," real-time online display, validation of probability, and beginning the development of an ERC module for the Statistical Hurricane Intensity Prediction Scheme (SHIPS). 
Wimmers submitted a First-year report (Wimmers, 2016b) on 30 September 2016. In this document, Wimmers laid out significant milestones for the project and forecasted completion dates. For reporting period Jan-Jun 2016: real-time online display finished in June 2016, evaluation of online module display finished in June 2016, production of online technical documentation finished in June 2016, and validation of probability was at $90 \%$ completion. Model verification used Kossin's dataset of valid ERC events from aircraft reconnaissance.

In 2017, the principal investigators published a presentation (Wimmers et al., 2017) on the project that included a summary of the product. ARCHER had been successfully adapted to "analyze the full range of eyewall patterns out from the center-fix point." Real-time display of analysis as a "forecasting/diagnostic aid" had been finished. A third point affirms to "integrate this information into a new, microwave-based ERC prediction tool." The presentation further details existing ERC tools: E-SHIPS and pERC. The former "applies ERC climatology to an existing TC" and "requires forecaster to already know that an ERC is underway." The latter "predicts probability of secondary eyewall formation using environmental variables and geostationary satellite data" but "does not use microwave imagery." At this point, MPERC model and Ring Score are still separate graphs, and it was determined to add the MPERC model to the real-time ARCHER-ERC diagnostic webpage; in other words, further work was needed to combine the two into a full online display of the algorithm.

In 2017, Wimmers submitted a report (Wimmers, 2017a) on 30 March 2017. Validation of ERC probability was completed in February 2017. Finalization of double eyewall ARCHER module for performance optimization was completed in December 2016. The online display of the algorithm was at $90 \%$ with completion in May 2017. MPERC model was completed to "diagnose ERC-onset using microwave information" and appeared "to perform remarkably well." Concerning online display, the MPERC probabilities were to be integrated as a column in the hovmuller plots and was expected to be finished by May 2017, "well ahead of the 2017 North Atlantic hurricane season."

Wimmers submitted a progress report (Wimmers, 2017b) on 29 September 2017. The online display of ARCHER MPERC was completed in May 2017, and the completion of online technical documentation was at $90 \%$. In the document, it was reported that the hovmullers are now in the "intended form." An analysis of a hovmuller from Hurricane Irma of 2017 was provided as an example for interpreting the hovmuller. It details that ERCs: can be identified by their common characteristic of an outer branch of relative maximum scores merging with the more intense inner branch and increasing the radius of the new eye. (p. 6)

The predictive model appears to perform well; however, it was mentioned that the principal investigators are still "developing optimal methods of interpreting the probabilistic results" and seek to utilize such results "in an intensity prediction scheme." The principal investigators aimed to finalize the evaluation of model performance at "various intensities, shear environments, data availability, and so on" at the end of the 2017 Atlantic Hurricane Season.

On 30 March 2018, Wimmers submitted a progress report (Wimmers, 2018a) detailing the completion of online technical documentation in February 2018 and the delivery of ERC module for SHIPS, with the latter at 50\% completion and expected completion in June 2018. The documentation "was produced as a wiki collaborative document hosted at Space Science and Engineering Center (SSEC)." It establishes the guidelines for interpreting the model and is based on the 2017 Atlantic Hurricane Season. Concerning the ERC module, it is stated "the model is now in its final form" and was determined to be "working at an optimal level of accuracy." The 50\% completion reported stems from the fact that the model is "ready for incorporation into SHIPS, but this work on incorporation is still underway."

Wimmers submitted a final report (Wimmers, 2018b) on 29 November 2018. The document presents summaries of accomplishments of the project from the period of July 2015 to September 2018. It was reported that the creation of real-time online text file output for the ERC module for SHIPS was completed in June 2018, while the delivery of that product is yet to be confirmed and remained at $50 \%$.

Results 


\section{Atlantic Hurricane Season}

In 2017, there was a total of nineteen tropical systems, of which seventeen were named, one TD, and one PTC. MPERC is not available for TSs Arlene, Bret, Cindy, and TD Four. PTC Ten has an analysis from the NHC but no ARCHER directory since it was added post-season. MPERC predicted ERCs in Hurricanes Irma, Jose, and Maria, with five, two, and two events, respectively. In total, MPERC predicted nine ERCs across three storms.

Hurricane Irma (2017 11L)

The NHC's official report (Cangialosi et al., 2018) on Hurricane Irma, in addition to Ring Score, validates four predictions out of five (Figure 2). ERC onsets were assigned at approximately 09/05 12:00 (5 September 1200 UTC), 09/06 09:00 (6 September 0900 UTC), 09/07 15:00 (7 September 1500 UTC), 09/08 15:00 (8 September 1500 UTC), and 09/10 00:00 (10 September 0000 UTC).

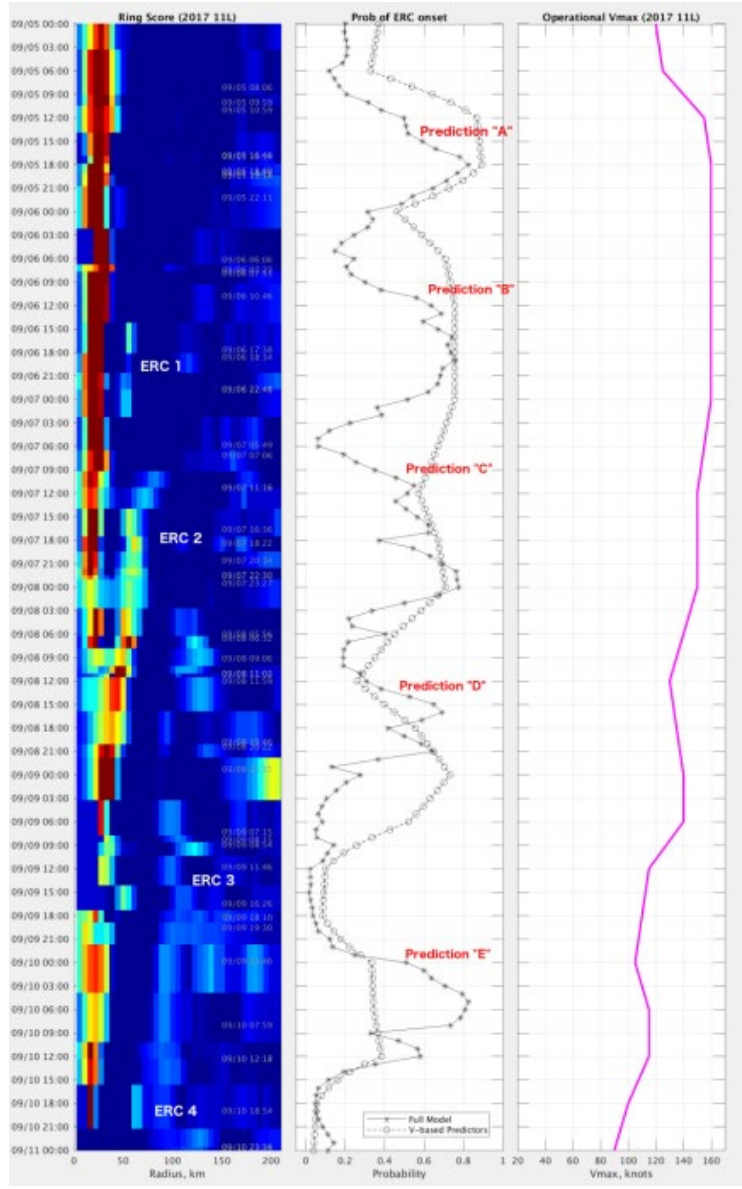

Figure 2. Five predictions from Irma, of which four were valid.

However, the official report states:

Irma fluctuated between category 2 and 3 strength from 00001 September to 0000 UTC 4 September. The main causes for the intensity fluctuations were likely eyewall replacement cycles and intrusions of dry air. (p. 2)

By early on 4 September... Irma was on a strengthening trend once again, likely due to the completion of an eyewall replacement cycle. (p. 3)

Subsequent re-analysis of the hovmullers at the time period specified in the above quotes was conducted. Looking at the Ring Score, it is not out of the question ERCs occurred. From 1 September to 4 September, the eyewall intensity fluctuated. Concerning the probability, two spikes of Full Model appear to have crossed the threshold 
of over $50 \%$, however, both instances were not substantiated after initial onset and were therefore not considered indications (Figure 3).
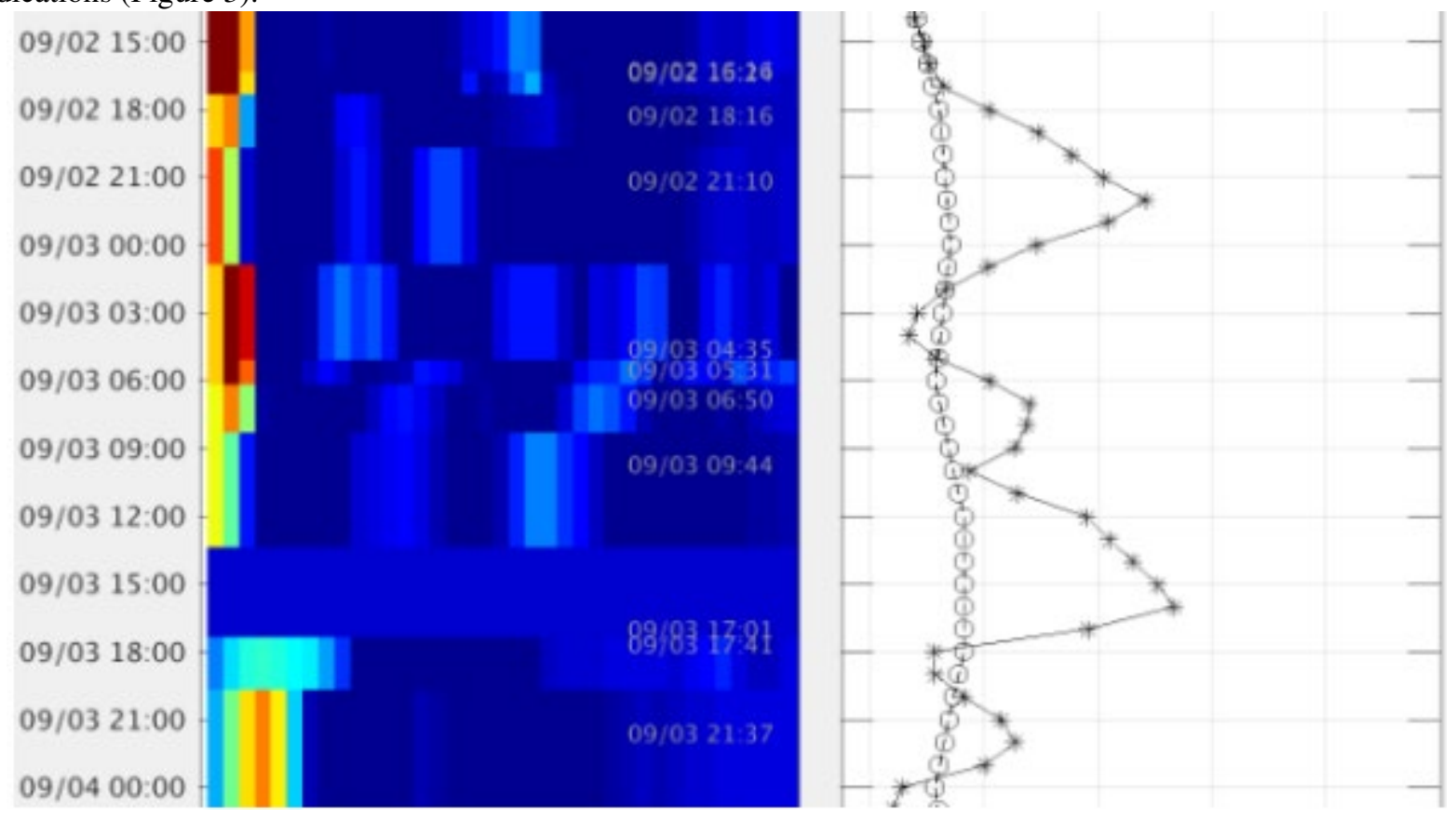

Figure 3. Two un-sustained predictions crossing 50\%.

Therefore, it was concluded that the actual number of ERCs that occurred in Hurricane Irma was six.

Hurricane Jose (2017 12L)

The NHC's official report (Berg, 2018a) on Hurricane Jose, in addition to Ring Score, validates only one event out of two (Figure 4). ERC onsets were assigned around 09/08 21:00 (8 September 2100 UTC) and 09/10 12:00 (10 September 1200 UTC). According to the report:

The northwestward track took Jose away from the northern Leeward Islands toward the southwestern Atlantic through early on 11 September, and an increase in northeasterly shear and a partial eyewall replacement caused the hurricane to weaken below major hurricane intensity by 0600 UTC that day. (p. 2)

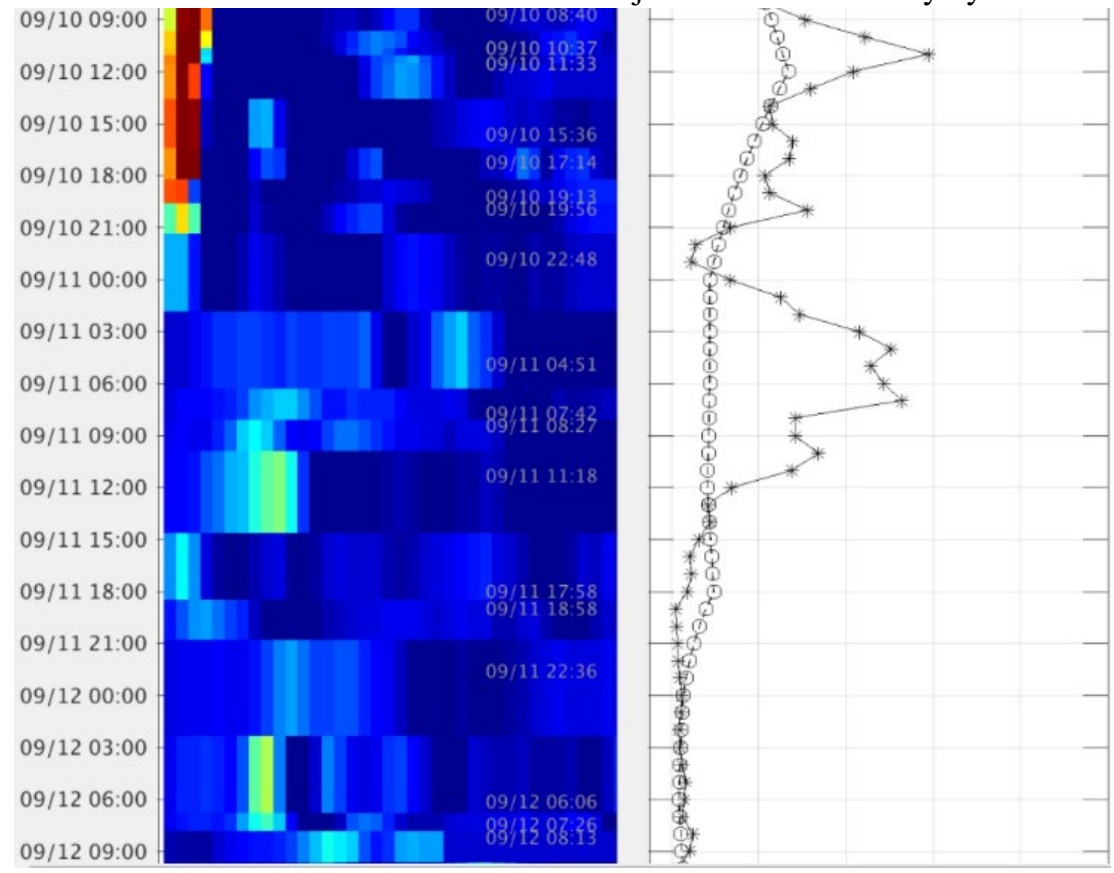


Figure 4. Validated ERC for Jose.

However, there is some ambiguity with this ERC. There again seems to an unsubstantiated ERC occurring at approximately 09/11 03:00 (11 September 0300 UTC). Ring Score was taken into account for the onset assigned on 10 September and the onset assigned on 11 September. The official report reads "partial eyewall replacement," suggesting the 11 September is the correct assignment. Despite this, it is still in the realm of possibility that an ERC was ongoing from 10 September being within the 9-hour weakening and 20-hour strengthening phases.

It was ultimately decided to validate the 10 September assignment.

Hurricane Maria (2017 15L)

The NHC's official report (Pasch et al., 2019b) on Hurricane Maria, in addition to Ring Score, validates one ERC out of two (Figure 5). ERC onsets were assigned at roughly 09/18 12:00 (18 September 1200 UTC) and 09/19 15:00 (19 September 1500 UTC). According to the report:

20 September... Maria moved west-northwestward to northwestward toward Puerto Rico and, after reaching maximum intensity, underwent an eyewall replacement with an outer eyewall becoming more dominant by the time the center of the system reached Puerto Rico. (p. 2)

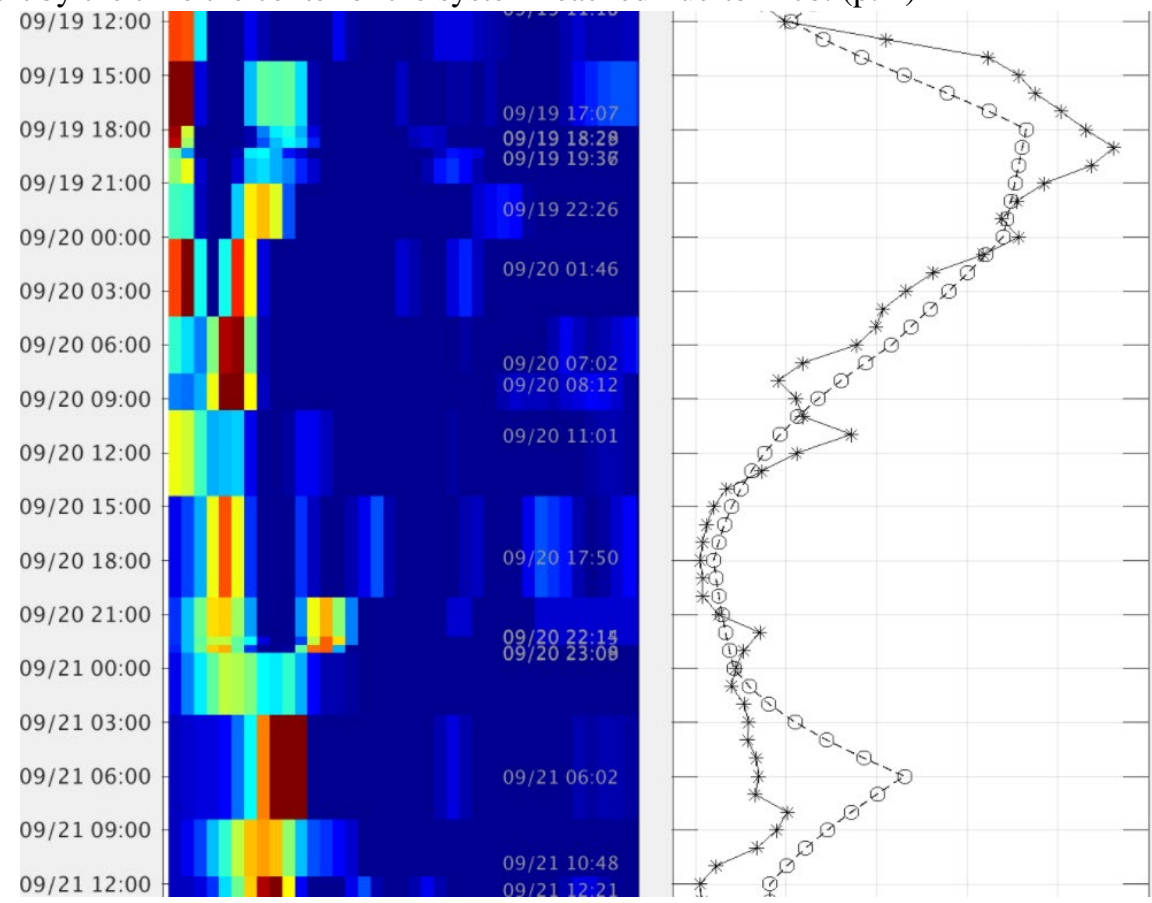

Figure 5. Valid ERC with supporting Ring Score for Maria.

\section{Hurricane Lee (2017 14L)}

MPERC did not predict the two ERCs indicated by the NHC for Hurricane Lee. Ring Score reflected the NHC's analysis, however, the probability did not cross 50\% in both cases (Figure 6). According to the NHC's official report (Blake, 2018b):

Late on 25 September, Lee completed an eyewall cycle, forming a larger eye in the process, and began to intensify again... [O]n 26 September... Lee again went through a quick $\sim 12$-h eyewall replacement that evening, which resulted in another increase in the eye diameter on 27 September. (p. 3) 

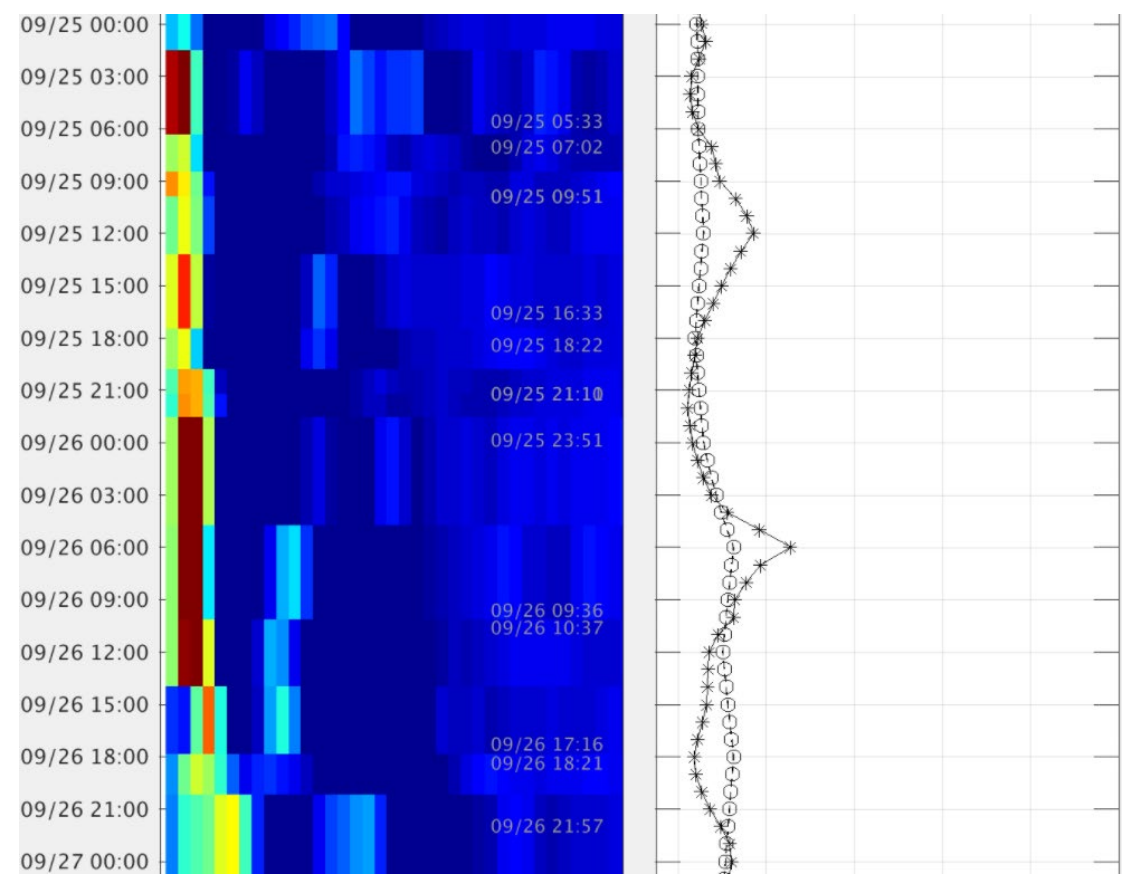

Figure 6. ERC on 25 September with weakened eyewall. ERC onset on 26 September with outer eyewall visible on Ring Score and weakened eyewall. Both instances do not have probabilities over $50 \%$.

\section{Results}

The actual number of ERCs that occurred in 2017 is ten, of which four were not indicated by MPERC at all.

Table 1. MPERC and NHC ERCs for each 2017 storm

\begin{tabular}{|l|l|l|l|}
\hline Name & Intensity & ERCs (NHC) & ERCs (MPERC) \\
\hline Arlene & TS & 0 & N/A \\
\hline Bret & TS & 0 & N/A \\
\hline Cindy & TS & 0 & N/A \\
\hline TD Four & TD & 0 & N/A \\
\hline Don & TS & 0 & 0 \\
\hline Emily & TS & 0 & 0 \\
\hline Franklin & C1 & 0 & 0 \\
\hline Gert & C2 & 0 & 0 \\
\hline Harvey & C4 & 0 & 0 \\
\hline PTC Ten & N/A & 0 & N/A \\
\hline Irma & C5 & 6 & 5 \\
\hline Jose & C4 & 1 & 2 \\
\hline Katia & C2 & 0 & 0 \\
\hline Lee & C3 & 2 & 0 \\
\hline Maria & C5 & 1 & 2 \\
\hline Nate & C1 & 0 & 0 \\
\hline Ophelia & C3 & 0 & 0 \\
\hline Philippe & TS & 0 & 0 \\
\hline Rina & TS & 0 & 0 \\
\hline Total & & 10 & 9 \\
\hline & & & \\
\hline
\end{tabular}




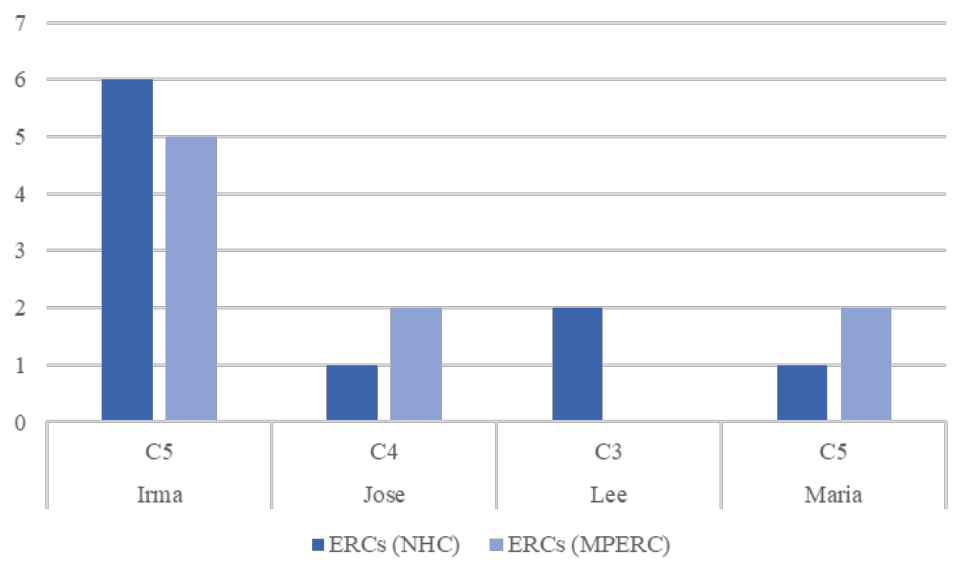

Figure 7. Number of ERCs for the respective storms for 2017.

\section{Atlantic Hurricane Season}

In 2018, there were sixteen tropical systems, of which fifteen were named and one TD. MPERC predicted ERC events in Hurricanes Florence and Michael, with each storm having one prediction. In total, MPERC predicted two ERCs across two storms.

Hurricane Florence (2018 06L)

The NHC's official report (Stewart \& Berg, 2019) on Hurricane Florence, in addition to Ring Score, validates the ERC prediction (Figure 8). ERC onset was assigned at approximately 09/11 18:00 (11 September 1800 UTC). According to the report:

Florence began to slowly weaken, likely due to the effects of cold upwelling and the onset of an eyewall replacement cycle (ERC). Data from Air Force Reserve and NOAA reconnaissance aircraft, along with passive microwave satellite imagery, indicated that the diameter of Florence's eye had increased to 25-30 n mi and eyewall convection had started to erode in the southeastern semicircle by late on 12 September. (p. 3)

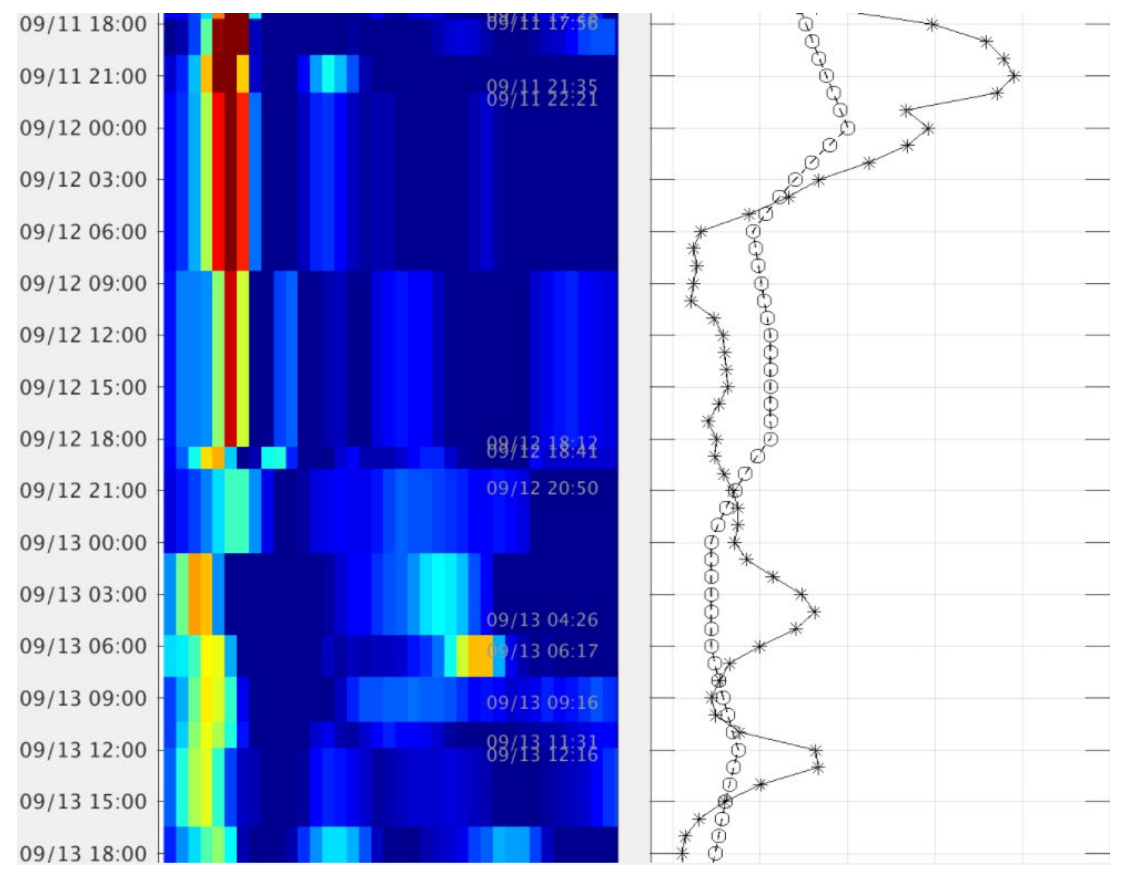


Figure 8. Verified Florence ERC indicated by weakening eyewall on 12 September.

\section{Hurricane Michael (2018 14L)}

The NHC's official report (Beven II et al., 2019) on Hurricane Michael disproves the only ERC prediction. ERC onset was assigned at around 10/10 09:00 (10 October 0900 UTC). According to the report:

This track resulted in the eye making landfall near Tyndall Air Force Base (AFB) in the Florida Panhandle, southeast of Panama City, near 1730 UTC [10 October]... Michael rapidly weakened after landfall. (p. 3)

\section{Results}

The actual number of ERCs that occurred in 2018 is one.

Table 2. MPERC and NHC ERCs for each 2018 storm.

\begin{tabular}{|l|l|l|l|}
\hline Name & Intensity & ERCs (NHC) & ERCs (MPERC) \\
\hline Alberto & TS & 0 & 0 \\
\hline Beryl & C1 & 0 & 0 \\
\hline Chris & C2 & 0 & 0 \\
\hline Debby & TS & 0 & 0 \\
\hline Ernest & TS & 0 & 0 \\
\hline Florence & C4 & 1 & 1 \\
\hline Gordon & TS & 0 & 0 \\
\hline Helene & C2 & 0 & 0 \\
\hline Isaac & C1 & 0 & 0 \\
\hline Joyce & TS & 0 & 0 \\
\hline TD Eleven & TD & 0 & 0 \\
\hline Kirk & TS & 0 & 0 \\
\hline Leslie & C1 & 0 & 0 \\
\hline Michael & C5 & 0 & 1 \\
\hline Nadine & TS & 0 & 0 \\
\hline Oscar & C2 & 0 & 0 \\
\hline Total & & 1 & 2 \\
\hline
\end{tabular}

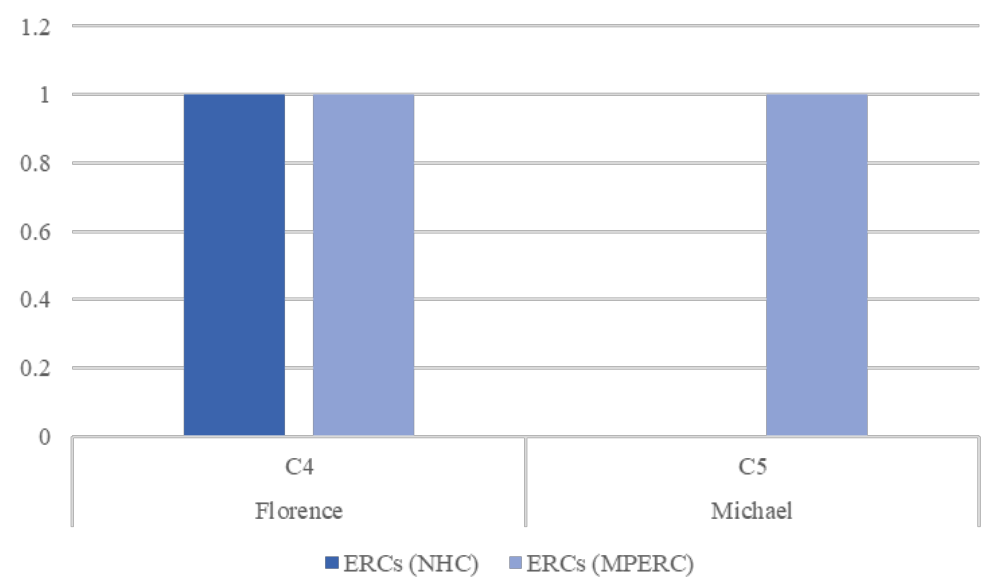

Figure 9. Number of ERCs for the respective storms for 2018. 


\section{Atlantic Hurricane Season}

In 2019, there was a total of twenty tropical systems, of which eighteen were named and two TDs. MPERC predicted ERC events in Hurricanes Dorian, Humberto, Jerry, and Lorenzo, with three, one, one, and one ERCs, respectively. In total, MPERC predicted six ERCs across four storms.

Hurricane Dorian (2019 05L)

The NHC's official report (Avila \& Stewart, 2020) on Hurricane Dorian, in addition to Ring Score, does not validate any ERC events. ERC onsets were assigned at around 08/31 03:00 (31 August 0300 UTC), 08/31 21:00 (31 August 2100 UTC), and 09/02 00:00 (2 September 0000 UTC). According to the report:

The rapid intensification process continued... Dorian became a category 5 hurricane and then made landfall at Elbow Cay, Great Abaco... at 1640 UTC 1 September... The eye made landfall near South Riding Point on Grand Bahama near 0215 UTC 2 September with 155-kt winds. It exited along the north coast of the island $6 \mathrm{~h}$ later... and the winds had decreased to $140 \mathrm{kt}$, likely due to the interaction with land and ocean cooling beneath the intense hurricane... [D]uring the period from 3-5 September... The hurricane then weakened as it moved northward toward and environment of high shear and cooler waters. (p. 3)

\section{Hurricane Humberto (2019 09L)}

The NHC's official report (Stewart, 2020) on Hurricane Humberto does not validate the prediction. ERC onset was assigned at approximately 09/18 09:00 (18 September 0900 UTC). According to the report:

[S]light strengthening occurred through 0000 UTC 19 September... Later that morning after passing to the north of Bermuda, Humberto began accelerating northwestward ahead of a broad trough and its associated cold front... During this time, the hurricane also began a steady weakening trend due to the increasing south-southwesterly vertical wind shear exceeding $50 \mathrm{kt}$ and entrainment of very dry mid-level air, despite the otherwise favorable sea-surface temperatures in excess of 27 degrees C. (p.3 )

\section{Hurricane Jerry (2019 10L)}

The NHC's official report (Brown, 2019a) on Hurricane Jerry, in addition to Ring Score, does not validate the event. ERC onset was assigned around 09/19 21:00 (19 September 2100 UTC). According to the report:

[D] ata from an Air Force Reserve Hurricane Hunter aircraft indicated that Jerry reached a peak intensity of 90 kt by 0000 UTC 20 September. Upon reaching peak intensity, strong northwesterly upper-level winds (around 250-mb level) and dry mid-level air caused the hurricane to quickly lose organization. Within these unfavorable conditions, Jerry rapidly weakened over the next $24 \mathrm{~h}$ while it moved quickly westnorthwestward... Jerry weakened to a tropical storm by 0000 UTC 21 September. (p.2 )

It is interesting to note that Hurricane Jerry is the only non-major hurricane to have an ERC prediction.

\section{Hurricane Lorenzo (2019 13L)}

The NHC's official report (Zelinsky, 2019b) on Hurricane Lorenzo validates an ERC not predicted by MPERC and additionally disproves the ERC prediction from MPERC. ERC onset was assigned at approximately 09/29 00:00 (29 September 0000 UTC). According to the report:

Lorenzo... reached an initial peak intensity of $125 \mathrm{kt}$ around 0000 UTC 27 September. Around that same time, the hurricane slowed and turned northwestward in response to a break that developed within the subtropical ridge. The combination of an eyewall replacement cycle and an intrusion of dry air into the inner core of the hurricane caused Lorenzo to weaken during the next 24 h. (p. 2)

Shear... caused Lorenzo's eyewall to collapse. Ocean cooling from extensive upwelling associated with the hurricane's large size likely also contributed to the decay of Lorenzo's convective structure. The hurricane consequently weakened to a category 2 storm by 1800 UTC 29 September. (p. 2) 
The mention of an ERC in the first quotation prompted a re-analysis of Hurricane Lorenzo. In a similar case to Hurricane Irma of 2017, the probability crossed 50\% at roughly 09/26 21:00 (26 September 2100 UTC), but was not substantiated and was therefore not considered a prediction. Looking at the Ring Score, it is indicative of an ERC (Figure 10).

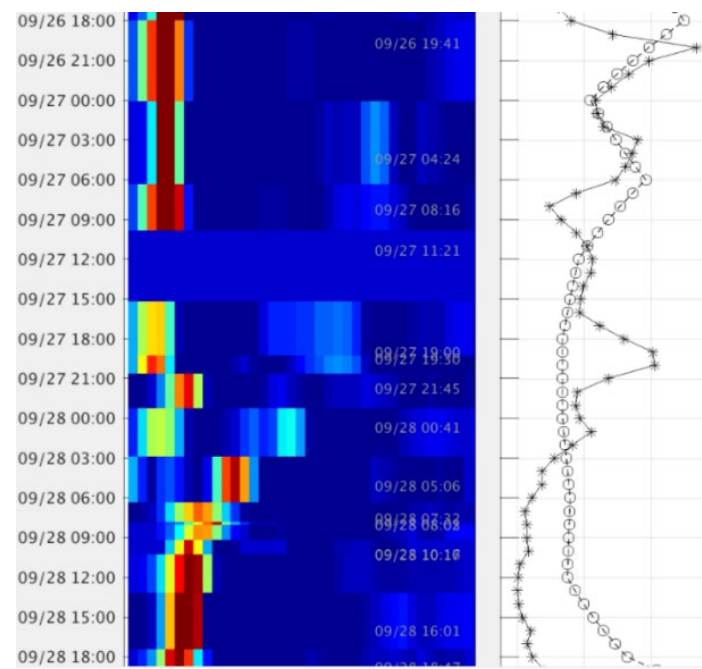

Figure 10. Probability crosses 50\%. Ring Score on 27 and 28 September clearly indicated secondary eyewall and the replacement of the inner eyewall.

\section{Results}

The actual number of ERCs that occurred in 2019 is one, which was not indicated by MPERC.

Table 3. MPERC and NHC ERCs for each 2019 storm.

\begin{tabular}{|l|l|l|l|}
\hline Name & Intensity & ERCs (NHC) & ERCs (MPERC) \\
\hline Andrea & TS (Subtropical) & 0 & 0 \\
\hline Barry & C1 & 0 & 0 \\
\hline TD Three & TD & 0 & 0 \\
\hline Chantal & TS & 0 & 0 \\
\hline Dorian & C5 & 0 & 3 \\
\hline Erin & TS & 0 & 0 \\
\hline Fernand & TS & 0 & 0 \\
\hline Gabrielle & TS & 0 & 0 \\
\hline Humberto & C3 & 0 & 1 \\
\hline Imelda & TS & 0 & 0 \\
\hline Jerry & C2 & 0 & 1 \\
\hline Karen & TS & 0 & 0 \\
\hline Lorenzo & C5 & 1 & 1 \\
\hline Melissa & TS & 0 & 0 \\
\hline TD Fifteen & TD & 0 & 0 \\
\hline Nestor & TS & 0 & 0 \\
\hline Olga & TS & 0 & 0 \\
\hline Pablo & C1 & 0 & 0 \\
\hline Rebekah & TS (Subtropical) & 0 & 0 \\
\hline
\end{tabular}




\begin{tabular}{|l|l|l|l|}
\hline Sebastien & TS & 0 & 0 \\
\hline Total & 1 & 6 \\
\hline
\end{tabular}

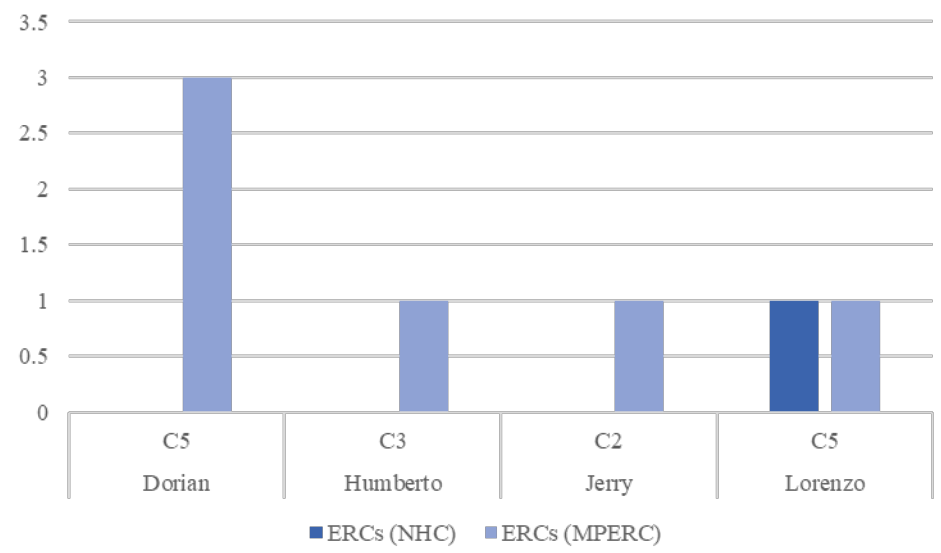

Figure 11. Number of ERCs for the respective storms for 2019.

\section{Conclusion}

\section{Number of ERCs}

In total, MPERC predicted seventeen ERC events in nine TCs. Of the seventeen predictions, seven were valid (Figure 14). Five ERCs were not indicated by MPERC: two in Hurricane Irma, two in Hurricane Lee, and one in Hurricane Lorenzo. ARCHER MPERC predicted only around 41\% of ERCs that occurred over the course of 2017 to 2019. The lack of understanding of the genesis and process of ERCs makes it so difficult to predict events. Because of this, ARCHER MPERC appears to perform remarkably well. Nevertheless, it is clear that because of environmental conditions, such as the presence of shear and dry air intrusion, ARCHER MPERC produces erroneous results, examples of which can be found in Hurricane Humberto and Hurricane Jerry (Figures 12 and 13).

Table 4. Number of ERCs for each storm with an ERC, both NHC and MPERC.

\begin{tabular}{|l|l|l|l|}
\hline Name & Intensity & ERCs (NHC) & ERCs (MPERC) \\
\hline Irma & C5 & 6 & 5 \\
\hline Jose & C4 & 1 & 2 \\
\hline Lee & C3 & 2 & 0 \\
\hline Maria & C5 & 1 & 2 \\
\hline Florence & C4 & 1 & 1 \\
\hline Michael & C5 & 0 & 1 \\
\hline Dorian & C5 & 0 & 3 \\
\hline Humberto & C3 & 0 & 1 \\
\hline Jerry & C2 & 0 & 1 \\
\hline Lorenzo & C5 & 1 & 1 \\
\hline Total & & 12 & 17 \\
\hline
\end{tabular}




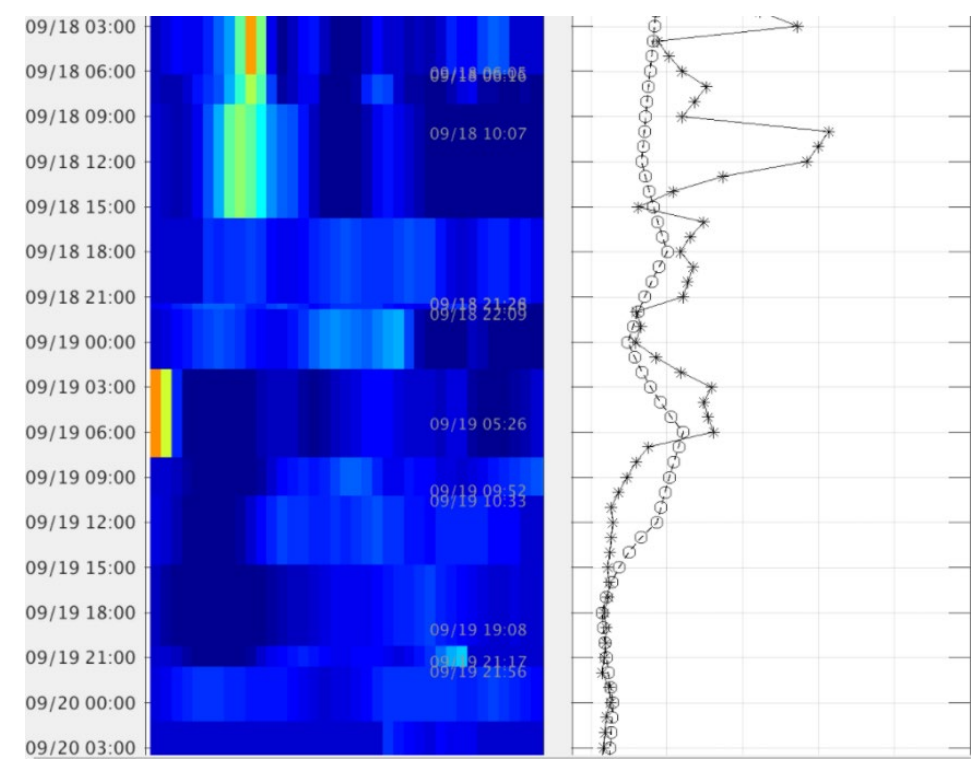

Figure 12. Humberto's prediction caused by noisy gradients from wind shear.

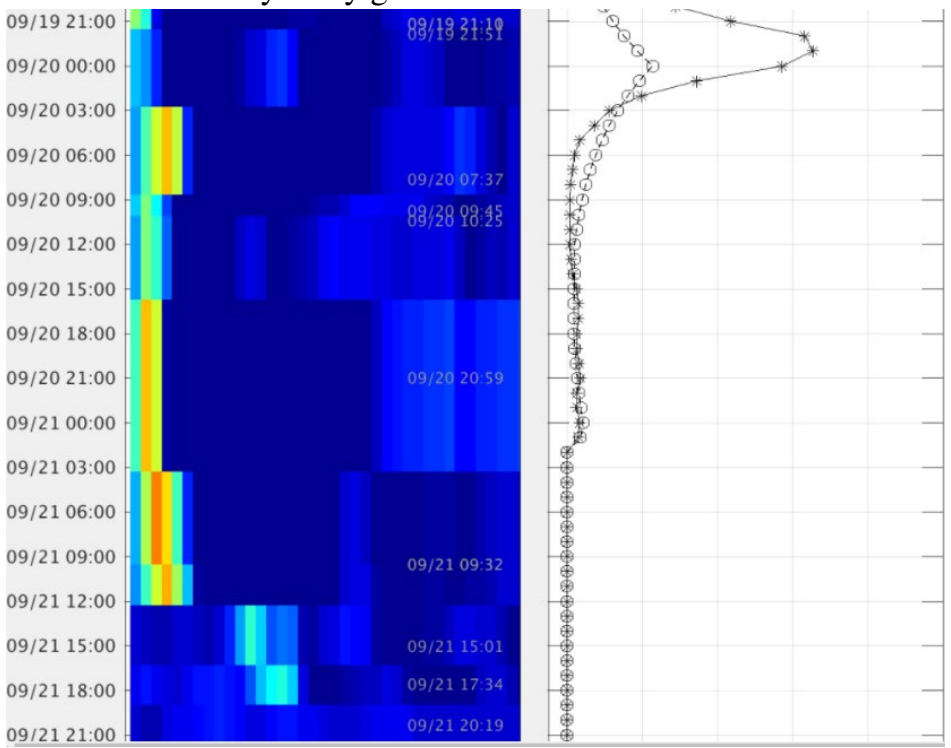

Figure 13. Jerry's prediction caused by dry air intrusion and shear.

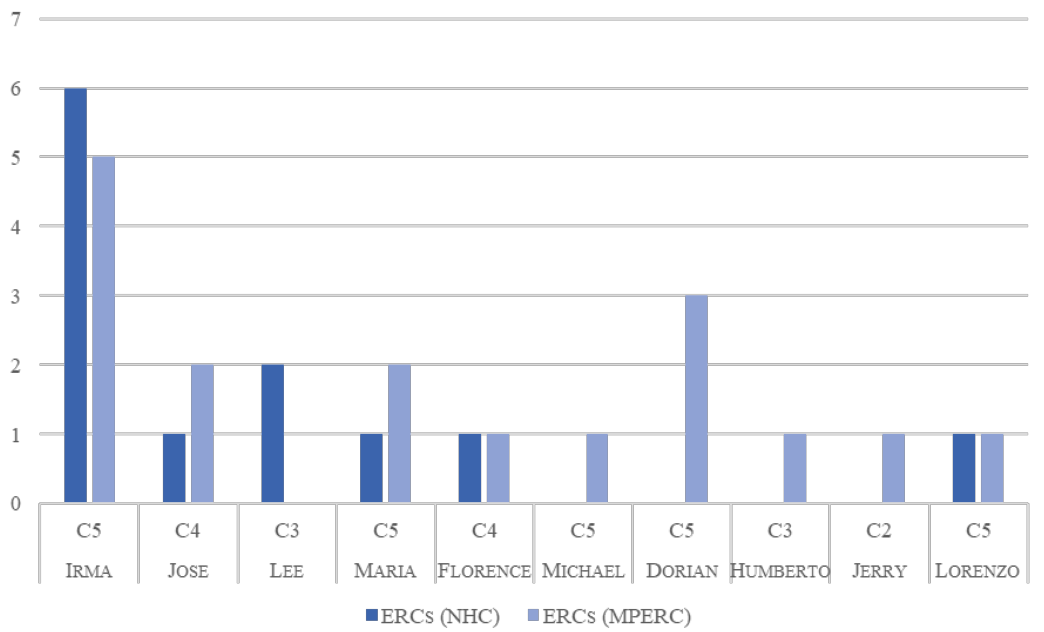


Figure 14. NHC and MPERC ERCs for each storm with an ERC.

\section{Intensity}

Concerning intensity, MPERC predicted the most ERCs in category 5 hurricanes at twelve predictions (Figure 15). MPERC did not predict any ERCs in category 1 storms, TSs, and TDs. NHC analyses reflected this.

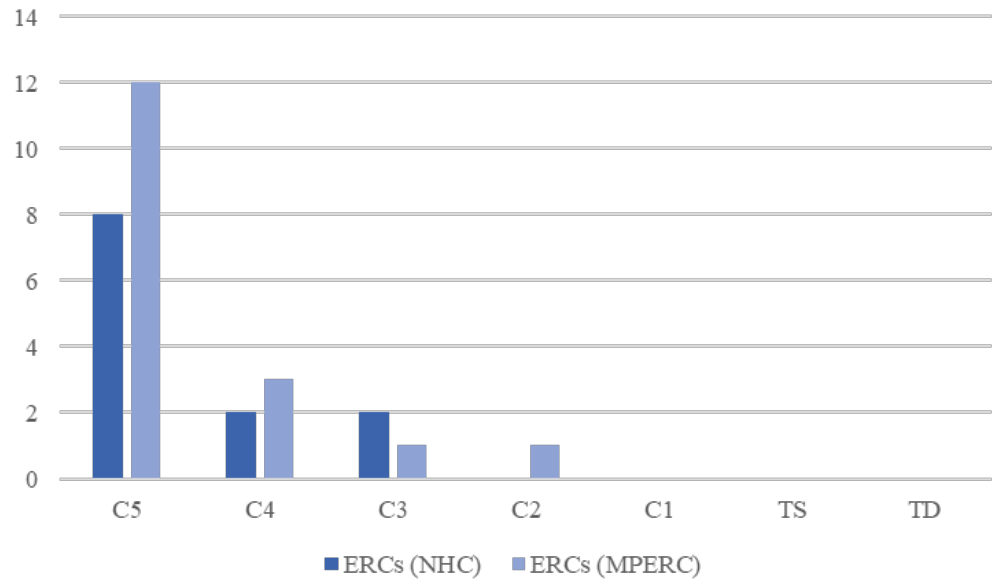

Figure 15. Number of ERCs per category (intensity).

\section{Impact and Implications}

The impact and importance of ARCHER MPERC lie in the intensity forecasting accuracy of TCs. ERC events can broaden the wind field, generating greater storm surge, thus reducing the already small window of time for preparation and evacuation (Sitkowski et al., 2011). RI can take place after an ERC, resulting in a more intense TC (Sitkowski et al., 2011). The algorithm is crucial for understanding and predicting ERCs and offers analysis and diagnostic tools for a phenomenon that warrants understanding. This would allow for suitable warning during weather-related emergencies (Wimmers, 2018b).

\section{Acknowledgements}

I would like to thank my research mentor, Leya M. Joykutty, for assisting and guiding me.

\section{References}

ARCHER (Automated Rotational Center Hurricane Eye Retrieval). (n.d.). Retrieved from http://tropic.ssec.wisc.edu/real-time/archerOnline/web/index.shtml

Avila, L. A. (2017, October 20). Tropical Depression FOUR [PDF]. NHC.

Avila, L. A. (2018, November 9). Tropical Depression Eleven [PDF]. NHC.

Avila, L. A. (2019a, February 14). Hurricane Katia [PDF]. NHC.

Avila, L. A. (2019b, November 1). Tropical Depression Fifteen [PDF]. NHC.

Avila, L. A., \& Fritz, C. L. (2018, September 20). Hurricane Beryl [PDF]. NHC.

Avila, L. A., \& Stewart, S. R. (2020, April 20). AL052019_Dorian_final_20200427 [PDF]. NHC. 
Berg, R. (2018a, February 20). Hurricane Jose [PDF]. NHC.

Berg, R. (2018b, January 26). Tropical Storm Cindy [PDF]. NHC.

Berg, R. (2018c, October 18). Tropical Storm Alberto [PDF]. NHC.

Berg, R. (2019a, December 31). Tropical Storm Melissa [PDF]. NHC.

Berg, R. (2019b, January 30). Tropical Storm Joyce [PDF]. NHC.

Berg, R. (2019c, October 25). Tropical Storm Chantal [PDF]. NHC.

Beven II, J. L. (2018, March 12). Hurricane Franklin [PDF]. NHC.

Beven II, J. L. (2019, April 2). Tropical Storm Ernesto [PDF]. NHC.

Beven II, J. L. (2020a, January 27). Hurricane Pablo [PDF]. NHC.

Beven II, J. L. (2020b, January 3). Tropical Storm Gabrielle [PDF]. NHC.

Beven II, J. L., \& Berg, R. (2018, April 5). Hurricane Nate [PDF]. NHC.

Beven II, J. L., Berg, R., \& Hagen, A. (2019, May 17). Hurricane Michael [PDF]. NHC.

Blake, E. S. (2017, December 19). Tropical Storm Don [PDF]. NHC.

Blake, E. S. (2018a, December 14). Hurricane Chris [PDF]. NHC.

Blake, E. S. (2018b, February 13). Hurricane Lee [PDF]. NHC.

Blake, E. S. (2019a, January 29). Tropical Storm Kirk [PDF]. NHC.

Blake, E. S. (2019b, November 15). Tropical Storm Erin [PDF]. NHC.

Blake, E. S., \& Zelinsky, D. A. (2018, May 9). Hurricane Harvey [PDF]. NHC.

Brennan, M. J. (2018, March 5). Tropical Storm Bret [PDF]. NHC.

Brown, D. P. (2017, January 26). Potential Tropical Cyclone Ten [PDF]. NHC.

Brown, D. P. (2018, January 31). Tropical Storm Philippe [PDF]. NHC.

Brown, D. P. (2019a, December 11). Hurricane Jerry [PDF]. NHC.

Brown, D. P. (2019b, February 19). Hurricane Oscar [PDF]. NHC.

Brown, D. P. (2020, February 3). Tropical Storm Sebastien [PDF]. NHC.

Brown, D. P., Latto, A., \& Berg, R. (2019, May 16). Tropical Storm Gordon [PDF]. NHC.

Cangialosi, J. P. (2017, July 5). Tropical Storm Arlene [PDF]. NHC.

Cangialosi, J. P. (2018, January 9). Tropical Storm Rina [PDF]. NHC.

Cangialosi, J. P. (2019, July 20). Hurricane Helene [PDF]. NHC.

Cangialosi, J. P., \& Ramos, N. A. (2019, December 16). Tropical Storm Karen [PDF]. NHC.

Cangialosi, J. P., Hagen, A. B., \& Berg, R. (2019, November 18). Hurricane Barry [PDF]. NHC.

Cangialosi, J. P., Latto, A. S., \& Berg, R. (2018, June 30). Hurricane Irma [PDF]. NHC.

CIMSS Tropical Cyclones. (n.d.). Retrieved from http://tropic.ssec.wisc.edu/

Courtney, J., Langlade, S., Barlow, S., Birchard, T., Knaff, J., Kotal, S., . . Singh, A. (2020, February 19).

Operational perspectives on tropical cyclone intensity change Part 2: Forecasts by operational agencies. Retrieved 
from https://www.sciencedirect.com/science/article/pii/S2225603220300035, https://doi.org/10.1016/j.tcrr.2020.01.003

Courtney, J., Langlade, S., Sampson, C., Knaff, J., Birchard, T., Barlow, S., . . Shimada, U. (2019, November 25). Operational Perspectives on Tropical Cyclone Intensity Change Part 1: Recent advances in intensity guidance. Retrieved from https://www.sciencedirect.com/science/article/pii/S2225603219300694, https://doi.org/10.1016/j.tcrr.2019.10.002

Description of the product pages. (n.d.). Retrieved from https://groups.ssec.wisc.edu/groups/archer/description-ofthe-product-pages

Hagen, A. B., Blake, E., \& Berg, R. (2020, February 28). Tropical Storm Nestor [PDF]. NHC.

Highlights. (n.d.). Retrieved from https://groups.ssec.wisc.edu/groups/archer/highlights

How ARCHER works. (n.d.). Retrieved from https://groups.ssec.wisc.edu/groups/archer/how-archer-works

Index of /real-time/archerOnline/cyclones. (n.d.). Retrieved from http://tropic.ssec.wisc.edu/realtime/archerOnline/cyclones/

JHT Overview. (n.d.). Retrieved from https://www.nhc.noaa.gov/jht/

Kossin, J. (2020, February 25-26). Upgrades to the M-PERC and PERC Models to Improve Short Term Tropical Cyclone Intensity Forecasts [PDF]. NHC.

Kossin, J., \& Sitkowski, M. (2012, April 1). Predicting Hurricane Intensity and Structure Changes Associated with Eyewall Replacement Cycles. Retrieved from https://journals.ametsoc.org/view/journals/wefo/27/2/waf-d-1100106_1.xml?rskey=rsHmpc, https://doi.org/10.1175/WAF-D-11-00106.1

Latto, A. S. (2019, August 6). Subtropical Storm Andrea [PDF]. NHC.

Latto, A., \& Berg, R. (2020, February 7). Tropical Storm Imelda [PDF]. NHC.

M-PERC introduction. (n.d.). Retrieved from https://groups.ssec.wisc.edu/groups/archer/archer-erc-introduction

Molinari, J., Zhang, J., Rogers, R., \& Vollaro, D. (2019, June 1). Repeated Eyewall Replacement Cycles in Hurricane Frances (2004). Retrieved from https://journals.ametsoc.org/view/journals/mwre/147/6/mwr-d-180345.1.xml?rskey=NmJ0xP, https://doi.org/10.1175/MWR-D-18-0345.1

NHC Data Archive. (n.d.). Retrieved from https://www.nhc.noaa.gov/data/

Pasch, R. J. (2019, March 28). Tropical Storm Debby [PDF]. NHC.

Pasch, R. J. (2020, January 14). Tropical Storm Fernand [PDF]. NHC.

Pasch, R. J., \& Roberts, D. P. (2019, March 29). Hurricane Leslie [PDF]. NHC.

Pasch, R. J., Berg, R., \& Hagen, A. B. (2020, March 19). Tropical Storm Olga [PDF]. NHC.

Pasch, R. J., Latto, A. S., \& Cangialosi, J. P. (2019a, February 14). Tropical Storm Emily [PDF]. NHC.

Pasch, R. J., Penny, A. B., \& Berg, R. (2019b, February 14). Hurricane Maria [PDF]. NHC.

Sitkowski, M., Kossin, J., \& Rozoff, C. (2011, December 1). Intensity and Structure Changes during Hurricane Eyewall Replacement Cycles. Retrieved from https://journals.ametsoc.org/view/journals/mwre/139/12/mwr-d-1100034.1.xml?rskey=NmJ0xP, https://doi.org/10.1175/MWR-D-11-00034.1

Stewart, S. R. (2018a, March 17). Hurricane Gert [PDF]. NHC.

Stewart, S. R. (2018b, March 27). Hurricane Ophelia [PDF]. NHC.

Stewart, S. R. (2019a, December 9). Subtropical Storm Rebekah [PDF]. NHC. 
Stewart, S. R. (2019b, March 22). Tropical Storm Nadine [PDF]. NHC.

Stewart, S. R. (2020, February 19). Hurricane Humberto [PDF]. NHC.

Stewart, S. R., \& Berg, R. (2019, May 30). Microsoft Word - AL062018_Florence_final_update_20190530 [PDF]. NHC.

Suggested uses. (n.d.). Retrieved from https:/groups.ssec.wisc.edu/groups/archer/suggested-uses

Wimmers, A. (2016a). JHT_Wimmers_midYear1 [PDF]. NHC.

Wimmers, A. (2016b, September 30). Wimmers_yr1_annualrpt.pdf [PDF]. NHC.

Wimmers, A. (2017a, March 30). Microsoft Word - JHT_Wimmers_Year1.5 [PDF]. NHC.

Wimmers, A. (2017b, September 29). Wimmers_197_progress_report4_092917.pdf [PDF]. NHC.

Wimmers, A. (2018a, March 30). Wimmers_midyear3.pdf [PDF]. NHC.

Wimmers, A. (2018b, November 29). Wimmers_197_progress_reportFINAL_113018.pdf [PDF]. NHC.

Wimmers, A., \& Velden, C. (2010, September 1). Objectively Determining the Rotational Center of Tropical Cyclones in Passive Microwave Satellite Imagery. Retrieved from https://journals.ametsoc.org/view/journals/apme/49/9/2010jamc2490.1.xml?tab_body=fulltext-display, https://doi.org/10.1175/2010JAMC2490.1

Wimmers, A., Herndon, D., \& Kossin, J. (2016). Ihc16wimmers-s04-08.pdf [PDF]. NHC.

Wimmers, T., Herndon, D., \& Kossin, J. (2017). Improved Eyewall Replacement Cycle Forecasting Using ARCHER - a Modified Microwave-Based Algorithm (Year 2) [PDF]. NHC.

Zelinsky, D. A. (2019a, August 19). Tropical Depression Three [PDF]. NHC.

Zelinsky, D. A. (2019b, December 16). Hurricane Lorenzo [PDF]. NHC.

Zelinsky, D. A. (2019c, January 30). Hurricane Isaac [PDF]. NHC.

Zhou, X., \& Wang, B. (2011, May 1). Mechanism of Concentric Eyewall Replacement Cycles and Associated Intensity Change. Retrieved from https://journals.ametsoc.org/view/journals/atsc/68/5/2011jas3575.1.xml?rskey=NmJ0xP, https://doi.org/10.1175/2011JAS3575.1 